\title{
Complications of laser Dermatologic Treatments
}

\author{
Vladimir Filaj ${ }^{1 *}$, Erisa Kola ${ }^{2}$, Ina Kola ${ }^{1}$
}

Received: 02 June 2021 / Accepted: 21 June 2021 / Published online: 20 July 2021

This article is published with open access at https://journal.astes.org.al

(C) The author(s) 2021.\& Copyright (C) 2021, the Albanian Society for Trauma and Emergency Surgery

(c) The Albanian Journal of Trauma and Emergency Surgery is an Open Access Journal. All articles are distributed under the terms of the Creative Commons Attribution Non-Commercial License: http://creativecommons.org/licenses/by-nc/4.0/) which permits unrestricted non-commercial use, distribution, and reproduction in any medium provided the original work is properly cited.

\begin{abstract}
Over the past three decades, the indications for the use of lasers have increased dramatically. Combined with the interest paid by the media, the volume of laser procedures has progressively increased, as has the number of complications arising from their use.

Knowing the principles behind laser surgery can help minimize the potential for complications; however, as with all surgical procedures, in addition to excellent surgical results, undesirable results are inevitable.

Laser technologies have evolved effectively these past decades with a broader spectrum of clinical applications accompanied by improved outcomes. Cutaneous lasers and lights are considered safe interventions with an associated rapid healing time. Post-treatment consequences are usually mild and spontaneously resolving, with erythema and edema lasting hours to days. More troublesome while less common adverse events include urticaria, erosions, blistering, infection, hyperpigmentation, hypopigmentation, burns and delayed re-epithelialization [2]. We present some clinical cases with some serious adverse effects of the laser treatments in women and men. There are some treatment options on how to reduce the complications or manage them without long term sequelae, however the clinical experience of the laser operator and the accurate device used influences the safety and the outcomes of the treatment.
\end{abstract}

Keywords: Laser treatment, burns after laser treatment, laser complications

\section{Introduction}

The first lasers used to treat skin diseases occurred over 40 years ago, they were used to treat benign vascular birth marks such as port wine spots and hemangiomas. In the last 20 years, advances in laser technology have revolutionized their use in treating many skin conditions and congenital defects, including vascular and pigmented lesions, and the removal of tattoos, scars, and wrinkles. There is a range of laser and light technologies available for skin surface and rejuvenation.[1]

Anderson and Parrish have an outstanding role in the development of safer and more effective laser systems. They proposed the theory of photo thermolysis where they

Original article, no submission or publication in advance or in parallel

* Corresponding author:

Vladimir Filaj M.D, Ph.D.

$\bowtie$ drvfilaj@yahoo.com

1 Department of Burns and Plastic Surgery, University Hospital Center "Mother Teresa", Tirana, ALBANIA

2 Department of Pathology, Tirana, ALBANIA. describe the mechanism in which specific tissue destruction occurs with minimal adjacent injury through the application of specific laser wavelengths and controlled delivery methods [3].

Despite all the improvements of these techniques to destroy targeted tissue, side effect and complications remain a risk.

Burns are considered rare adverse events of laser treatments. They can also result from cooling failures, including both excessive and insufficient epidermal cooling.

Safe use of the deeply penetrating long-pulsed laser is particularly dependent on adequate cooling, and burns, skin necrosis, and attendant scar formation have been reported not infrequently when cooling has been insufficient.

Any laser or device at high energy settings can result in shallow burns in the shape of the device tip. These are especially seen as parallel rectangular red patches associated with overly aggressive treatment with intense pulsed light devices [4].

Despite the satisfying results achieved by the use of laser in dermatology, this special treatment modality is still in continuous evolution [5]. 


\section{Methods}

We present some cases with severe adverse effects following laser treatments in both men and women. downtime, during which re epithelialization occurs, and there are erosions and exposed dermis. Usually, this downtime is uneventful and a few days in duration, but sometimes it can be complicated by superficial infections, which
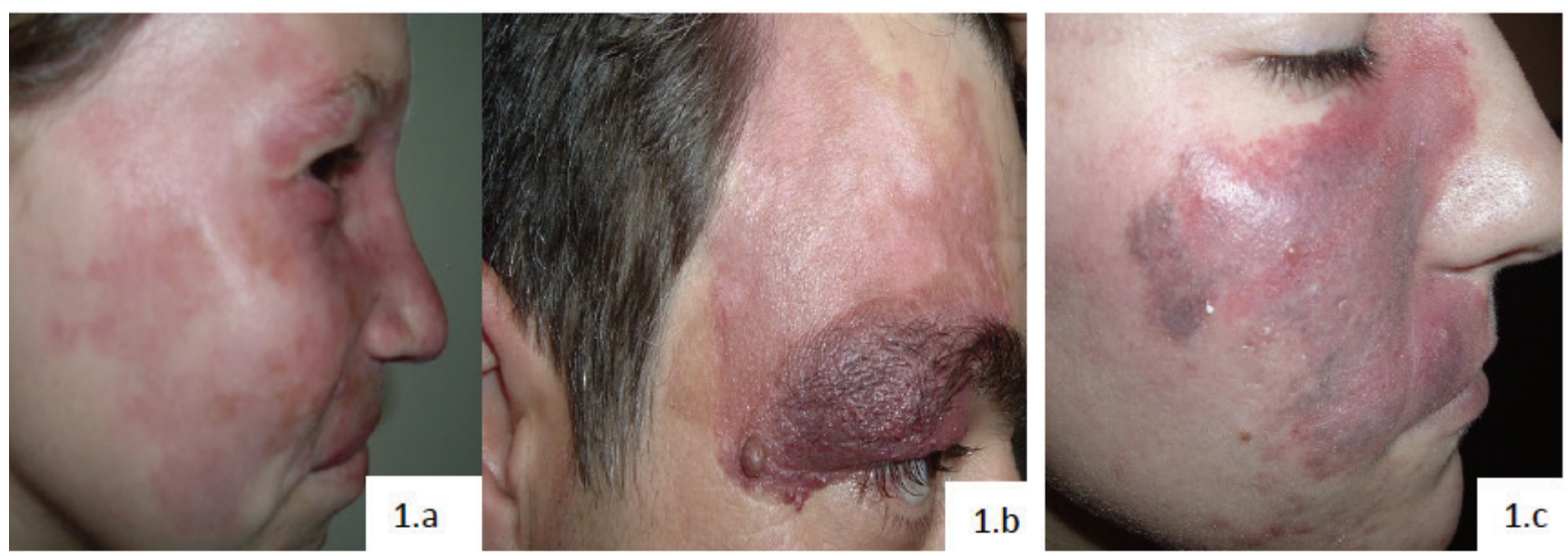

Figure $1(a, b, c$,) Adverse effects after laser treatment, in women. These most severe adverse effect includes burns that need careful approach to avoid developing scars and long-term sequelae.
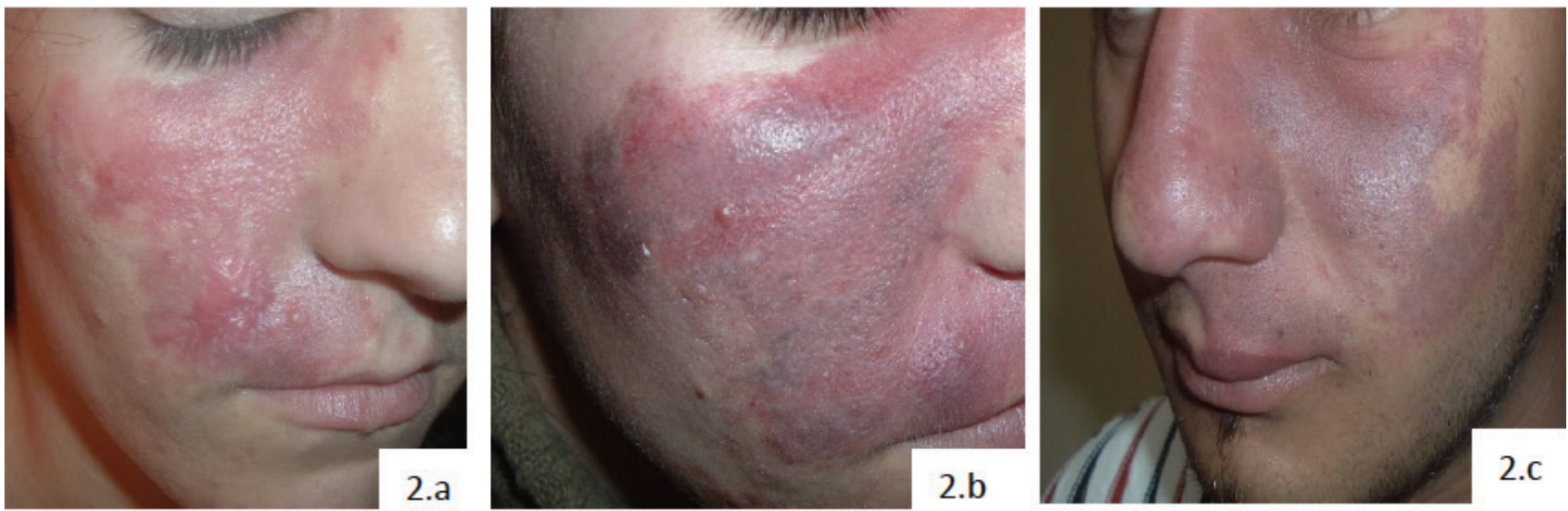

Figure $2(a, b, c)$, Adverse effects after laser treatment, in men and women. These most severe adverse effect includes burns that need careful approach to avoid developing scars and long-term sequelae.

Burns may occur by a failure of the cooling techniques or from overheating the tissue through excessive heat generation. Patients may also report excessive pain, especially when compared to past treatments.

The clinical presentation is very different and can range from prolonged erythema to ulcerations and necrosis. Clinically ulcerations from cutaneous burns can look similar to infections such as herpes virus infection.

\section{Discussion}

Overall, current laser and light devices for cutaneous use are considered very safe. For non-ablative devices, common expected consequences rarely exceed mild and spontaneously resolving erythema, edema, and bruising. Ablative and partially ablative devices have an associated need to be treated when identified. The most problematic outcomes after laser are associated with thermal injury. The complication occurred as a result of deep thermal injury associated with the use of highly penetrating near infrared wavelengths [6].

A variety of causes can predispose a patient to develop such an injury, which can result in blistering, healing with post inflammatory pigmentation change, and sometimes eventual textural change or scarring. Various cooling technologies, when used correctly, can reduce the risk of cutaneous burns. Treatment of device burns is similar to that of burns caused by other means. Prompt application of ice may reduce the area of injury. Topical steroids and bland emollients may accelerate re-epithelialization and reduce the risk of pigmentation abnormality or scar. If appropriate, prophylactic antibiotics may reduce the risk of infection. 


\section{Conclusions}

Laser procedures should be performed with great caution as a great part of laser treatments are for cosmetic purposes. Patients should be aware that laser procedures are generally safe, but that lasers are complex devices, interactions between tissues and lasers are not perfectly understood. However, in case of adverse effects, they can be managed and improved, either quickly or through a more prolonged series of appropriate steps. Proper patient selection, appropriate technique and optimization of wound care management would significantly reduce the risk of complications. Thus when recognized and managed promptly the severity and duration of complications will be minimized.

COI Statement: This paper has not been submitted in parallel. It has not been published nor submitted for consideration beforehand.

This research received no specific grant from any funding agency in the public, commercial, or nonprofit sectors. There are no relevant or minor financial relationships from authors, their relatives or next of kin with external companies.

\section{Conflict of Interest Statement}

There is no conflict of interest

\section{References}

1. Alexiades-Armenakas MR, Dover JS, Arndt KA. The spectrum of laser skin resurfacing: Nonablative, fractional, and ablative laser resurfacing. J Am Acad Dermatol 2008; 58 : 719-37. PubMed.

2. Tanzi EL, Lupton JR, Alster TS. Lasers in dermatology: four decades of progress. J Am Acad Dermatol. 2003 Jul;49(1):131; quiz 31-4.

3. Anderson RR, Parrish JA. Selective photothermolysis:precise microsurgery by selective absorption of pulsed radiation. Science. 1983 Apr 29; 220(4596): 524-7. PMid:6836297.

4. Prohaska J, Hohman MH. Laser Complications. In: StatPearls. Treasure Island (FL):StatPearls Publishing; 2021. https:// www.ncbi.nlm.nih.gov/books/NBK532248

5. Gianfaldoni S, Tchernev G, Wollina U, et al. An Overview of Laser in Dermatology: The Past, the Present and ... the Future (?). Open Access Maced J Med Sci. 2017;5(4):526-530. Published 2017 Jul 23. doi:10.3889/oamjms.2017.130

6. Willey A, Anderson RR, Azpiazu JL, Bakus AD, Barlow RJ. Complications of laser dermatologic surgery. Lasers Surg Med. 2006 Jan;38(1):1-15. doi: 10.1002/1sm.20286. PMID: 16444692 . 